\title{
Status and Development Trend Analysis of China's Natural Gas Metering Technology
}

\author{
Yi Su, Zewei Xu, and Kedong Luo
}

\begin{abstract}
Natural gas flow metering is a key procedure in the process of natural gas production, transportation and sales, and it is also the main basis for enterprises to carry on trade transition, economic analysis and cost reduction. Firstly the significance of developing natural gas metering technology is analyzed, and the present development situation of natural gas metering technology at home and abroad is introduced, including the current situation of foreign natural gas metering technology, domestic natural gas measurement standard system, calibration technology and methods, quantity traceability system, energy metering system, etc. Secondly, challenges faced by natural gas metering technology in china are pointed out. Finally, according to China's natural gas industry development strategy, the future development trend of natural gas metering technology is forecasted and analyzed.
\end{abstract}

Index Terms-Natural gas, metering technology, measurement standard, quantity traceability system, energy metering.

\section{INTRODUCTION}

In recent years, with the rapid development of economy, the optimization of energy structure adjustment and the promotion of environmental protection in China, the proportion and demand of natural gas in primary energy structure has been increasing continuously year by year, which leads to that the natural gas industry in China has entered in a booming and prosperous era. Traditional gas management scheduling model cannot meet the requirements of the new era. Therefore, in order to promote the development of natural gas trade, natural gas metering has received increasing attention. The accurate measurement of natural gas flow is the foundation of fair trade of natural gas, its economic calculation and cost analysis. In this sense, the accuracy of flow metering is directly related to the enterprises' economic benefits and consumers' interests. Accordingly, natural gas flow metering technology in the new era should meet the requirement in term of the following aspects.

(1) Instantaneity. The metering instantaneity refers to the quick and accurate respond to changes of market demand for natural gas, so as to facilitate enterprises to arrange production, to optimize pipeline operation, as well as to

Manuscript received January 25, 2016; revised May 19, 2016

$\mathrm{Yi} \mathrm{Su}$ is with the School of Business, Renmin University of China and the PetroChina Planning and Engineering Institute, Beijing 100083, PR China (e-mail: suyee830916@163.com).

Zewei Xu is with the 91 Financial Information Service (Beijing) Co., Ltd., Beijing, 100888, PR China (e-mail: 28661618@qq.com).

Kedong Luo is with the PetroChina Planning and Engineering Institute, Beijing 100083, PR China (e-mail: luokedong@petrochina.com.cn). maximize economic benefits.

(2) Accuracy. The metering accuracy is the premise for natural gas fair trade, and the basis of natural gas inventories optimization, gas transfer loss reduction, and rational allocation of gas supply and marketing.

(3) Economy. The metering economy is the economic indicator of evaluating gas metering costs. Therefore, in order to improve enterprises' economic efficiency, advanced metering technologies should be adopted to reduce the cost of flow metering.

\section{Flow MEtering TECHNOLOGY StATUS IN CHINA AND ABROAD}

Natural gas metering technology is used to determine the flow of natural gas. Generally, it is obtained by indirect measurement, whose accuracy depends on the overall performance of the measurement system [1]. In order to improve the accuracy of gas flow metering, unified technical standards need to be adopted for the comprehensive management of the natural gas flow metering system. Therefore, it is very necessary to establish a comprehensive metering standard system.

Natural gas metering is affected by various factors, so there are a lot of relevant metering standard systems, among which the natural gas flow metering standard is the most important one. In addition, there are some other standards of characteristic parameter calculation and measurement, such as calorific value, density, composition, compression factor etc. Meanwhile, some other standards related to design, safety, instruments and meters also exist.

\section{A. Flow Metering Technology Abroad}

Studies of technologies of the natural gas metering are rather early in foreign countries. Currently, there have been a series of complete metering standard systems, laws, regulations and policies, also including lots of advanced measuring instruments. In 1998, the ISO (International Organization for Standardization) issued ISO 13686 gas quality index [2]. The standard specifies three basic requirements which natural gas quality has to comply with, including health and safety standards, economic benefit and environmental protection standards, and also provides the methods for measuring the quality of the natural gas, controlling parameters and measurement units, as shown in Fig. 1.

According to ISO 13686, it firstly needs to form a complete set of natural gas metering technology standard system. Secondly, it also needs to establish gas sampling analysis standard, online and offline gas component analysis standard, 
sulfide, particulate matter, mercury and other trace component analysis standard, as well as measurement and calculation methods of natural gas physical parameters, such as hot spots, density, water dew point and hydrocarbon dew point, and so on, to form a complete quantity traceability chain.

$$
\text { Quality index }\left\{\begin{array}{l}
\text { Physical properties }\left\{\begin{array}{l}
\text { (1) Main components: methane, ethane, propane, total butane } \\
\text { total pentane, } C_{6}^{+}, \text {nitrogen, carbon dioxide } \\
\text { (2) Minor components: hydrogen, total unsaturated hydrocarbon } \\
\text { oxygen, carbon monoxide, helium } \\
\text { (3) Microcomponents: hydrogen sulfide, mercaptan } \\
\text { hydroxy sulfur, total sulfur, moisture }
\end{array}\right. \\
\text { (1) Relative density } \\
\text { (2) Compression factor } \\
\text { (3) Dew point }
\end{array}\right.
$$

As for flow metering standards, researchers have established a series of flow metering standards after a large number of experiments and relevant application data analysis were conducted [3], some of which are typical standards such as natural gas hole plate flowmeter standard (AGANo.3), gas turbine flow meter standard (No.7 AGA), gas ultrasonic flowmeter measurement standard (No.9 AGA) and natural gas compression factor calculation standard (ISO/DIS12213), etc. The establishment of these standards is of great significance to the development of natural gas metering technology. Table I lists the technical parameters of main gas flow calibration equipment [4].

TABLE I: MAJOR Foreign Gas Flow CALIBRATION DEVICE PARAMETERS

\begin{tabular}{ccccc}
\hline \hline Institutes & Country & Flow range & Pressure $(\mathrm{MPa})$ & Uncertainty \\
\hline NMI & Netherlands & $1 \sim 4\left(\mathrm{~m}^{3} \cdot \mathrm{h}^{-1}\right)$ & 1.01 & $0.01 \%(\mathrm{k}=2)$ \\
CRI & USA & $43.0 \mathrm{~kg} / \mathrm{s}$ & 10 & $0.1 \%(\mathrm{k}=2)$ \\
CRI & USA & $4.6 \mathrm{~kg} / \mathrm{s}$ & 1.4 & $0.1 \%(\mathrm{k}=2)$ \\
CEESI & USA & $4.55 \mathrm{~kg} / \mathrm{s}$ & 12.4 & $0.1 \%(\mathrm{k}=2)$ \\
CEESI & USA & $0.09 \mathrm{~kg} / \mathrm{s}$ & 12.4 & $0.1 \%(\mathrm{k}=2)$ \\
CEESI & USA & $0.47 \mathrm{~kg} / \mathrm{s}^{-1}$ & 10.3 & $0.1 \%(\mathrm{k}=2)$ \\
PigSar & Germany & $8 \sim 6500\left(\mathrm{~m}^{3} \cdot \mathrm{h}^{-1}\right)$ & $1.5 \sim 5$ & $0.19 \%(\mathrm{k}=2)$ \\
PigSar & Germany & $25 \sim 480\left(\mathrm{~m}^{3} \cdot \mathrm{h}^{-1}\right)$ & 9 & $0.02 \%(\mathrm{k}=2)$ \\
TCC & Canada & $50 \sim 50000\left(\mathrm{~m}^{3} \cdot \mathrm{h}^{-1}\right)$ & $*$ & $0.3 \%(\mathrm{k}=2)$ \\
\hline \hline
\end{tabular}

In addition, OIML (International Organization of Legal Metrology) also issued R140 standard system entitled the gas fuel metering system [5]. The standard system clearly defined the accuracy degree of gas flow metering system, and the maximum permissible measurement error of the physical parameters under the corresponding level, such as the quality of natural gas, energy, volume, pressure, temperature, density, compression factor and so on, as shown in Table II (all data in Table II are from OIML R140).

TABLE II: OIML R140 "GAS FuEL METERING SySTEM"

\begin{tabular}{lccc}
\hline \multirow{2}{*}{ Maximum permissible error } & \multicolumn{3}{c}{ Accuracy level } \\
\cline { 2 - 4 } & $\mathrm{A}$ & $\mathrm{B}$ & $\mathrm{C}$ \\
\hline Energy & $1.00 \%$ & $2.00 \%$ & $3.00 \%$ \\
Conversion volume or quality & $1.00 \%$ & $1.50 \%$ & $2.00 \%$ \\
Volume under the measuring & $0.70 \%$ & $1.20 \%$ & $1.50 \%$ \\
Standard volume or conversion quality & $0.50 \%$ & $1.00 \%$ & $1.50 \%$ \\
Energy conversion & $0.50 \%$ & $1.00 \%$ & $2.00 \%$ \\
Temperature & $0.5{ }^{\circ} \mathrm{C}$ & $0.5{ }^{\circ} \mathrm{C}$ & $1{ }^{\circ} \mathrm{C}$ \\
Pressure & $0.20 \%$ & $0.50 \%$ & $1.00 \%$ \\
Density & $0.25 \%$ & $0.70 \%$ & $1.00 \%$ \\
Compression factor & $0.30 \%$ & $0.30 \%$ & $0.50 \%$ \\
\hline \hline
\end{tabular}

In recent years, the real flow calibration method began to rise in Europe and the United States, and there are a lot of famous research laboratories that have studied it, such as
Southwest Research Institute (SWRI), Colorado Experiment Engineering Station Institute (CEESI), The National Measurement Institute (NMI), etc. In this way, the natural gas flow rate is measured by tracing the source of the natural gas state parameters and physical parameters in close to the actual conditions.

\section{B. Current Status of Natural Gas Flow Metering Technology in China}

\section{1) Flow metering standard}

Domestic research on natural gas metering technology can be traced back as early as 1980s. Based on the existing international standard system, and combined with the specific requirements of the natural gas development, researchers carried out a lot of studies on technical requirements of natural gas metering system, natural gas quality control index and detection techniques and methods, and ultimately established the national standard system, which is composed of the national standard GB17820 "natural gas" and the national standard GB/T 18603 "gas metering system technical requirements" [6], forming a complete set of metering technology and methods, as well as relevant quantity traceability system.

As the unified standard of natural gas industry, GB17820 specifies the technical indicators and the general 
classification of the natural gas, which are shown in Table III (all data in Table III are from GB 17820-2012). The technical indexes listed in the table represent technological requirements of the natural gas, which are related to the environment protection, safety and health as well as the economic benefits; at the same time, some indicators have reached the international standard, which provides a reference for quality control and measurement of China's natural gas imports.

TABLE III: GB 17820-2012 GAS TECHNICAL INDEX

\begin{tabular}{lccc}
\hline \hline Item & $1^{\text {st }}$ class & $2^{\text {nd }}$ class & $3^{\text {rd }}$ class \\
\hline $\begin{array}{l}\text { High calorific } \\
\text { value } / M J . m^{-3}\end{array}$ & $\geqslant 36.0$ & $\geqslant 31.4$ & $\geqslant 31.4$ \\
$\begin{array}{l}\text { Total sulfur content } \\
\text { quality } /{\mathrm{mg} . m^{-3}}^{-3}\end{array}$ & $\leqslant 60$ & $\leqslant 200$ & $\leqslant 350$ \\
$\mathrm{H}_{2} \mathrm{~S} / \mathrm{mg}^{-3} \mathrm{~m}^{-3}$ & $\leqslant 6$ & $\leqslant 200$ & $\leqslant 350$ \\
Mole fraction $\left(\mathrm{CO}_{2}\right)$ & $\leqslant 2.0 \%$ & $\leqslant 3.0 \%$ & $*$ \\
Water dew point $/{ }^{\circ} \mathrm{C}$ & Handover is $5^{\circ} \mathrm{C}$ lower than transfer \\
\hline \hline
\end{tabular}

TABLE IV: GB/T 18603 TECHNICAL REQUIREMENTS OF METERING SYSTEM WITH DIFFERENT LEVELS

\begin{tabular}{lccc}
\hline $\begin{array}{l}\text { Designed capacity } \\
\left(Q_{\mathrm{nv}}\right) / m^{3} \cdot h^{-1}\end{array}$ & $Q_{\mathrm{nv}} \geqslant 500$ & $\begin{array}{c}500 \leqslant Q_{\mathrm{nv}} \\
55000\end{array}$ & $5000 \leqslant Q_{\mathrm{nv}}$ \\
\hline $\begin{array}{l}\text { Calibration system } \\
\text { for measurement }\end{array}$ & - & - & $\sqrt{ }$ \\
$\begin{array}{l}\text { Temperature } \\
\text { conversion }\end{array}$ & $\sqrt{ }$ & $\sqrt{ }$ & $\sqrt{ }$ \\
$\begin{array}{l}\text { Pressure conversion } \\
\text { Compression factor }\end{array}$ & $\sqrt{ }$ & $\sqrt{ }$ & $\sqrt{ }$ \\
$\begin{array}{l}\text { Density metering } \\
\text { Accuracy level }\end{array}$ & - & - & $\sqrt{ }$ \\
\hline \hline
\end{tabular}

GB / T 18603 is the metering station work standard system formed on the basis of OMIL R140 standard system and EN1776 standard system. It explicitly stipulates each technical index that will be used in natural gas metering system renovation or expansion [7] (seen in Table IV, all data are from GB/T 18603), and also provides the accuracy level requirements of metering system ancillary instruments (seen in Table V, all data are from GB/T 18603).

TABLE V: GB/T 18603 ACCURACY REQUIREMENTS OF METERING SYSTEM SUPPORTING INSTRUMENT

\begin{tabular}{lccc}
\hline \hline \multirow{2}{*}{ Parameter measurement } & \multicolumn{3}{c}{ Accuracy level } \\
\cline { 2 - 4 } & $\mathrm{A}(1,0)$ & $\mathrm{B}(2,0)$ & $\mathrm{C}(3,0)$ \\
\hline Temperature & $0.5^{\circ} \mathrm{C}$ & $0.5^{\circ} \mathrm{C}$ & $1.0^{\circ} \mathrm{C}$ \\
Pressure & $0.20 \%$ & $0.50 \%$ & $1.00 \%$ \\
Density & $0.35 \%$ & $0.70 \%$ & $1.00 \%$ \\
Compression factor & $0.30 \%$ & $0.30 \%$ & $0.50 \%$ \\
Online calorific value & $0.50 \%$ & $1.00 \%$ & $1.00 \%$ \\
Offline calorific value & $0.60 \%$ & $1.25 \%$ & $2.00 \%$ \\
Volume flow at work & $0.70 \%$ & $1.20 \%$ & $1.50 \%$ \\
Results of measurement & $1.00 \%$ & $2.00 \%$ & $3.00 \%$ \\
\hline \hline
\end{tabular}

In addition, in order to promote the application of GB17820 and GB/T18603, China has formulated more than 50 national and industrial technical standard systems (seen in Table VI), covering natural gas sampling, energy measurement, component analysis, flow detection, and physical property calculation, which initially formed the quality and metering technology standard system, and brought our country's natural gas measurement standard system in line with international standards.

TABLE VI: LIST OF NATURAL GAS QUALITY AND MEASUREMENT STANDARD

\begin{tabular}{lll}
\hline \hline No. & Standard number & Name of standards \\
\hline 1 & GB/T 13609-2012 & Gas sampling guideline \\
2 & GB/T 19205-2008 & Natural gas standard reference condition \\
3 & GB/T16781.1-2008 & Natural gas - Determination of mercury - Part 1: Sampling of mercury by chemisorption on iodine \\
4 & GB/T 16781.2-2010 & Natural gas - Determination of mercury - Part 1: Sampling of mercury by amalgamation on gold/ platinum alloy \\
5 & GB/T 21391-2008 & Metering natural gas flow with a gas turbine flowmeter \\
$\ldots \ldots$ & $\ldots \ldots$ & $\ldots \ldots$ \\
\hline \hline
\end{tabular}

\section{2) Flow metering quantity traceability system}

In recent years, China's natural gas flow quantity traceability gradually moves towards real flow testing, so that the natural gas real flow metering technology can develop rapidly. The indexes of the current major natural gas flow quantity traceability system are shown in Table VII (all data in Table VII are from different metering stations respectively), among which the natural gas flow primary standards of Chengdu station and Nanjing station have reached the world advanced level.

TABLE VII: DOMESTIC GAS FLOW QUANTITY TRACEABILITY SYSTEM

\begin{tabular}{llccc}
\hline \hline Name of institute & Name of standard device & Qmax $/ m^{3} \cdot h^{-1}$ & Design pressure/MPa & Uncertainty \\
\hline National Station & Workgroup (Turbine + Ultrasonic) & 8000 & 10 & $0.30 \%$ \\
Chengdu Substation & Primary (mt) & 320 & 4 & $0.10 \%$ \\
Chengdu Substation & Workgroup (Sonic nozzle) & 2555 & 4 & $0.25 \%$ \\
Nanjing Substation & Primary (mt) & 440 & 10 & $0.10 \%$ \\
Nanjing Substation & Secondary (Sonic nozzle) & 3160 & 10 & $0.25 \%$ \\
Nanjing Substation & Workgroup (Turbine + Ultrasonic) & 12000 & 10 & $0.32 \%$ \\
Chongqing Substation & Primary (PVTt) & 180 & 1.6 & $0.10 \%$ \\
Chongqing Substation & Workgroup (Sonic nozzle) & 1500 & 1.6 & $0.50 \%$ \\
\hline \hline
\end{tabular}

Meanwhile, Chengdu substation carried out capacity expansion and transformation. The flow quantity traceability system of the Chengdu substation after the transformation is shown in Table VIII. According to Table VIII (all data in it are from Chengdu substation), Chengdu substation increased the low pressure standard device whose uncertainty ranges from $0.05 \% \sim 0.076 \%$, meanwhile improves the uncertainty of the sonic nozzle secondary standard device from $0.25 \%$ to $0.20 \%$, so that the technical level and capability of Chengdu substation have reached the international advanced level. 
TABLE VIII: Flow QUANTITY TRACEABILITy SySTEM OF CHENGDU BRANCH AFTER RENOVATION

\begin{tabular}{cccc}
\hline \hline Name of standard device & Design pressure / MPa & Flow range $/ \mathrm{m}^{3} \cdot h^{-1}$ & Uncertainty $(\mathrm{k}=2)$ \\
\hline Primary standard (mt) & 6.3 & $5 \sim 440$ & $0.05 \% \sim 0.076 \%$ \\
Sonic nozzle secondary standard & 6.3 & $5 \sim 5115$ & $0.20 \%$ \\
Ultrasonic mobile standard & 5 & $40 \sim 8000$ & $0.33 \%$ \\
Turbine working standard & 10 & $16 \sim 8000$ & $0.29 \%$ \\
\hline \hline
\end{tabular}

Additionally, China has also developed 9 primary standard reference materials and more than 10 types of secondary reference materials for natural gas analysis, and initially formed natural gas analysis quantity traceability chain, to ensure the accuracy and the traceability of natural gas analysis. Furthermore, in order to meet the development trend of more varieties and more sources, the preparing system of natural gas analysis standard reference material system which is under construction by PetroChina Southwest Oil can complete the production of the standard reference material system whose minor component uncertainty is better than $0.5 \%$.

\section{3) Natural gas energy metrology system}

The energy measurement of natural gas is indirectly obtained by natural gas flow measurement and high calorific value measurement, and its corresponding energy metering system mainly includes the flow meter, calorimeter, component analyzer and flow computer. The flow meter is used to measure natural gas volume flow, and its types mainly include waist wheel flowmeter, orifice flowmeter, ultrasonic flowmeter and turbine flowmeter, among which orifice flowmeter is more popular in China; the calorimeter is used to measure natural gas higher heating value, generally by the combustion calorimeter. It has two forms: the water and air flow. The uncertainty of the water flow calorimeter developed by National Institute of Metrology is less than or equal to $1.0 \%(k=2)$, and its newly developed oxygen bomb calorimeter has an uncertainty less than or equal to $0.6 \%$ $(k=2)$. In addition, the uncertainty of the primary measuring device under the construction of PetroChina is $0.2 \% \sim 0.25 \%$ $(k=2)$, which is equivalent to ISO15971 [8].

At present, China has gradually improved the gas volume flow metering technology and the calorific value metering technology and its related technologies, and meanwhile established the energy measurement standard system and natural gas quantity traceability system. In addition, in order to further improve the standardization of natural gas energy metrology, China has also formulated the GB/T 22723 "natural gas energy metering" [9] and some relevant implementation regulations, and also carried out some practical application in the first parts and the second parts of the project of natural gas transmission from West to East China, acquiring numerous application data, enriching the implementation experience and greatly promoting the development of China's natural gas energy metrology [10].

\section{The Challenges FACED By China's NATURAL GAS FLOW METERING TECHNOLOGY}

At the end of 2012, China issued the "gas" 12th five-year "development plan" [11]. According to the 12th five-year plan, China's natural gas pipeline is expected to be more advanced, whose main artery will be composed of gas transmission from West to East China, gas Transmission from Sichuan to East China and Shan-Jing line, and meanwhile will realize the connectivity of each part from gas production, storage to consumption across the country, to form a complete natural gas pipeline network and further ensure the stability, security, diversity and adequacy of the natural gas supply.

In 2013, China issued the natural gas measurement development plan in 2013-2020 [12]. According to this plan, by 2020 , the development of China's natural gas metering technology will reach the international level, measurement standard system and legal construction will be more perfect, and the timeliness, accuracy and economy of gas flow metering will be further improved, which basically meet the demand of China's natural gas industry development.

Therefore, after comprehensive analysis and examination of the background and trend of the natural gas industry in China, it can be seen that its development shall face the following challenges.

\section{A. Analytical Techniques}

At present, China has not established technologies and related standard systems yet, which will be specifically used to analyze and test the upstream natural gas and its micro trace components.

\section{B. Quantity Traceability System}

The quantity traceability system still needs to be further improved. For example, we need to improve the accuracy of gas calorific value metering devices and establish gas standard substances for the use of natural gas analysis, to meet the requirements of multi-gas sources and more varieties.

\section{Comparison of Gas Flow Quantity}

At present, China has not achieved the international key circulation ratio of gas flow quantity. Therefore, we need to further improve the international mutual recognition of laboratory data in the future.

\section{Flow Metering}

Galvanometer detection ability in China cannot meet the demand of the natural gas production, so we need to build a large diameter galvanometer to further improve its detection capability.

\section{TRend Analysis of Gas Flow Metering TECHNOLOGY IN CHINA}

Natural gas industry in China has entered a period of rapid development as its demand continues to increase. Meanwhile, competition in the natural gas market also intensifies greatly. In order to gain advantage in the fierce competition, three big state-owned oil companies have established new natural gas development strategies in the new era. However, in the 
development of natural gas industry, flow metering has become the main factor of curbing its development. Thus, metering gas flow fast, accurately and economically can not only effectively reduce the enterprise cost, and improve service quality, but also can make enterprises stand out in the fierce competition. Therefore, it is of great practical significance to forecast and research the development trend of natural gas metering technology.

Comprehensive analysis reveals that the future's natural gas metering technology will continue to develop in the following aspects.

\section{A. Automation, Intelligentialize and Remoteness of Metering Methods}

In recent years, with the rapid development of science and technology, gas metering is developing towards intelligentialize, automation and real-time performance, and at the same time using the Internet technology can realize remote control and online management of natural gas metering, such as SCADA (Supervisory Control And Data Acquisition) online monitoring system.

In natural gas flow metering system, flow meter data are only part of the data needed. In order to accurately meter gas flow, we need to measure gas pressure, temperature, density, gas chromatography, etc., which are usually performed by the auxiliary instrument system, and at the same time we also need to process, store, transmit and distribute measurement data through data processing.

\section{B. Promoting the Implementation of the Natural Gas Energy Measurement and Improving the Conversion of Natural Gas Metering Technology}

It is difficult for natural gas flow metering technology to reflect the real energy value of natural gas. With the constant improvement of China's economy and the internationalization of natural gas trade, different countries in the world proposed more and more requirements on natural gas fair trading, and energy measurement is the fairest method recognized by the world for natural gas trade. Therefore, the transfer from flow metering to energy metering is the only way for the development of natural gas measurement in China.

In addition, in order to promote the development of natural gas energy measurement, our country should greatly carry out research on natural gas energy metrology system and related supporting technology, such as improving the accuracy of gas calorific value measuring device, establishing gas standard substances for natural gas analysis, etc.

\section{Calibration and Quantity Traceability from Static Single Parameter to Dynamic Multi-parameters}

In the past, flowmeter calibration is realized through static single parameter. However, because of the dynamics of gas flow parameters, the quantity traceability becomes the most important factor which restricts the metering accuracy. At present, there is not a unified flow quantity standard, so the unification of the flow quantity is achieved mainly through the device alignment. However, the original standard of the flow quantity comparing device is a fixed flow standard device, and its working characteristics are different from flowmeters', so it cannot really reflect the dynamic characteristics of gas flow parameters. In recent years, the actual flow calibration technology developed quickly. The technology realizes the dynamic quantity traceability through measuring state parameters and physical parameters of natural gas in close to the actual conditions such as temperature, pressure, component and total flow. Therefore, the gas flow quantity traceability will gradually develop in the direction of the real flow calibration.

\section{Further Improving the Measurement Standard System}

A perfect measurement standard system is the foundation and basis for the implementation of gas flow metering. Combined with the international measurement standards, our country's measurement standard system is being gradually formed, and its contents keep enriching and perfecting, and develop in the direction of diverse standards. In addition, China should strengthen the gas measurement standard research in the field of the upstream area and unconventional natural gas area, to promote the independent innovation of science and technology; At the same time, China should also pay increasing attention to the internationalization promotion of domestic standards, for example, releasing multilingual national standards to adapt to the international gas trade market demand; Finally, in order to enhance the international influence of China, we should take an active part in international standard revision and formulation.

\section{E. Improving Measurement Technology}

China should develop the natural gas measurement technologies such as gas sampling, analysis, gas moisture measurement, poisonous and harmful trace component testing and so on. These technologies are the basis of gas quality control and evaluation and the technical reference of formulating related measurement standards.

\section{CONCLUSION}

Natural gas flow metering is not only an important foundation for gas trade between enterprises, but also an important technical index to assess and improve the efficiency of natural gas production. With the development of natural gas industry, how to acquire, process and analyze natural gas metering information fast, accurately and economically will become the key point of the gas flow metering technology, which can effectively reduce the cost of enterprise, improve the service quality, and make the enterprise gain more advantages in market competition. Therefore, China should strengthen the natural gas flow metering technology research, and make it progress rapidly and improve greatly, so as to promote gas fair trade, reduce production cost, improve economic benefit and social benefit.

\section{REFERENCES}

[1] A. L. Song, "Natural gas metering situation and development trend," Petroleum Instruments, vol. 20, pp. 6-8, 2012.

[2] Natural Gas Quality Designation, ISO 13686-1998.

[3] J. C. An and G. C. Liang, "Natural gas flow metering situation and development trend," Inner Mongolia Petrochemical Industry, vol. 20, pp. 42-45, 2013.

[4] X. M. Guo and F. Y. Zhang, "Discussion on dynamic quantity traceability system of natural gas," in Proc. National Conference on Flow Metering Academic Exchange, Beijing: The National Society for Flow Measurement, 2012, vol. 18, pp. 392-398. 
[5] Measuring System of Gaseous Fuel, OIML R140-1998.

[6] Natural Gas, GB 17820-2012.

[7] Natural Gas Metering System Technical Requirements, GB/T 18603-2001.

[8] W. H. Huang, Q. Luo and L. M. Huang, "Construction and development of natural gas energy measurement system in China," Oil and Natural Gas Chemical Industry, vol. 40, pp. 103-108, 2011.

[9] Natural Gas Energy Measurement, GB/T 22723-2008.

[10] L. M. Huang, "Status and prospect of natural gas quality and metering measurement technologies in China," Security and Management, vol. 34, pp. 117-122, 2014.

[11] $12^{\text {th }}$ Five-Year Plan of Natural Gas Development, National Development and Reform Commission, Beijing, 2012.

[12] Measuring Development Plan (2013-2020), State Council of the People's Republic of China, Beijing, 2013.

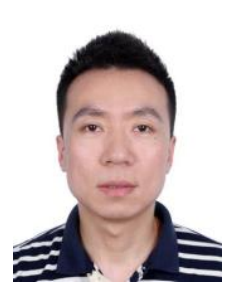

Yi Su was born in Tianshui, Gansu Province, China on August 21, 1983. Su successfully completed his B.Sc. degree in vehicle engineering and master's degree in mechanics and electronics engineering from Beijing University of Aeronautics and Astronautics, China in 2006 and 2009 respectively. He received his $\mathrm{PhD}$ degree in mechanics and electronics engineering from University of Science and Technology Beijing, China in 2013.

Now he is pursuing his postdoctoral study under the School of Business at Renmin University of China from 2013 and works as an intermediate engineer in PetroChina Planning and Engineering Institute where he mainly engages himself in the research of ERP (enterprise resource planning) system of natural gas and pipeline.

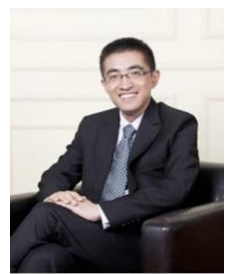

Zewei Xu was born in Beijing, China on September 6, 1983. $\mathrm{Xu}$ is a part-time professor of Beihang University Law School. Furthermore, he is also a member of Computing Expert Panel of Chinese Institute of Electronics, member of Big Data Expert Panel of China Computer Federation, member of Beijing Municipality Yanqing District Political Consultative Conference, member of All-China
Financial Youth Federation, standing committee member of Beijing Municipal Fengtai District Youth Federation, member of Internet Finance Panel of Asset Management Association of China, consultant of Internet Finance Panel of China Futures Association, researcher of Industry and Information Legalization Research Institute and mentor of Beijing Bank Maker Center, and mainly focuses his study on Internet finance, cloud computing, and big data, etc. Meanwhile, Xu has also won a lot of awards, which include $29^{\text {th }}$ "Beijing Youth May $4^{\text {th }}$ Medal", 2015 Zhongguancun High-end Leading Personnel, and Beijing Municipality Xicheng District "a hundred outstanding persons" and Youth Elite Talents, etc.

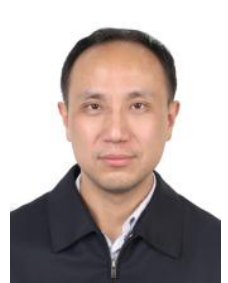

Kedong Luo was born in China on September 4, 1976. Luo successfully completed his B.Sc. degree in computer science from Tsinghua University, China in 1995. He received his master's degree and PhD degree in computer science from Tsinghua University, China in 2004.

After his graduation, he started to work in Petro China Planning and Engineering Institute and mainly focused his study on enterprise information system designing and construction, as well as information technology research and development. He was appointed as the vice director of Information Center in 2006. At present, he has been serving as the director of Information Center of Natural Gas and Pipeline since 2012. Meanwhile, he is a senior technical expert of China National Petroleum Corporation.

In recent years, as the project director and principal member, Dr. Luo has won more than 10 technical prizes, among which 5 prizes are provincial or ministry level. In 2006, Dr. Luo was given the title of "Informationization Advanced Individual in Group Company". In 2011, Dr. Luo has won the prize "National Petrochemical Industry Integration Advanced Individual". 